\title{
Evaluation Methodology for Ship's Planned Maintenance System Database
}

\section{Ladislav Stazić, Ivan Komar, Nikola Račić}

The paper describes an evaluation methodology for ship's Planned Maintenance System database based on the application of a newly created questionnaire and the analysis of the evaluation results received by the questionnaire. The evaluation results of several databases and the analysis of evaluation results are also shown in the paper.

The main purpose of the paper is to provide a simple and useful tool for the evaluation of all ships' Planned Maintenance System databases, which will enable users to examine the data in the database and discover the areas where the database and maintenance can and must be improved.

The expected outcome of the described methodology for the evaluation of ship's Planned Maintenance System database can be described as:

- Evaluating ship's Planned Maintenance System database,

- Performing ship's Planned Maintenance System database diagnostics to indicate insufficiencies,

- Determining the area and mode for ship's Planned Maintenance System database quality improvement and, consequently, overall improvement of the maintenance and reliability of ships' systems, - Setting up a standard for the development and evaluation of computerized database for ship's planned maintenance,

- Determining problems which occur during database development and describing complexity of the development process.

\section{KEY WORDS}

$\sim$ Planned Maintenance System

$\sim$ Database

$\sim$ Evaluation methodology

$\sim$ Questionnaire

$\sim$ Quality evaluation

University of Split, Faculty of Maritime Studies, Split, Croatia

e-mail: Istazic@pfst.hr

doi: 10.7225/toms.v06.n02.002

This work is licensed under (cc) BY

\section{INTRODUCTION}

Planned Maintenance Systems (PMS) for ships have been in use for quite a long time. PMS is regulated by ISM code, Chapter 10 (Revised ISM Code, 2015). Computerized programs for Planned Maintenance have been in use for more than thirty years. Despite the relatively long period of their application, the database quality, configuration and content are still open to various interpretations. The database quality depends of several key factors such as: the quality of raw data which must be entered into the database, experience and knowledge of the database factory team, priority given to the computerized PMS and databases, and care assigned to rechecking the data entered into the database (Tayi and Ballou, 1998). Shipping and the shipping industry cause shortcomings of these factors to become more pronounced and visible. Planned Maintenance database construction process is often without a good organization or a serious approach. Determining all the items that a Planned Maintenance database for a ship must have is often left to free interpretation of end users, or in better cases to the database construction team. This makes Planned Maintenance databases for ships very sensitive to shortcomings, especially in cases when the database is not checked and approved by a classification society (Machinery Survey Arrangements, 2003). At this point, a unique criterion or at least the recommendations which the Planned Maintenance database for ships should fulfil, do not exist. Every Planned Maintenance DB (database) for ships must have a certain number of maintenance items to fulfil the condition of quality maintenance. The list of these items does not exist either, and the databases can easily be constructed without one or more important pieces of equipment or machinery.

DQA (Data Quality Assessment) methodology (Batini et al., 2009) was chosen to be used to evaluate the data quality in PMS database. For the methodology, a questionnaire is created with the purpose to evaluate the data in PMS database. The questionnaire must be constructed following several conditions 
to meet the requirement of universal usage without any modifications. These conditions are that the evaluation criterion must be the same for all the computerized PMS for ships and all used Database Management Systems (DBMS), and the type of PMS and DBMS must not influence the evaluation grades at all.

The questionnaire shown in this paper is intended as an aid to the qualified personnel to help them evaluate PMS database, either one in use, or one after production. The personnel in this case must be qualified, i.e. they must have extensive knowledge of the computerized PMS system as well as knowledge of the ship's systems and equipment. That is a necessity which must be satisfied to obtain good and realistic evaluation results.

Evaluating the database with the use of the questionnaire will provide answers to the following questions:

- Is the data in PMS database for ships good quality?

- $\quad$ Are there serious deficiencies noted in the data in PMS database?

- $\quad$ Can the quality of the data in PMS database be improved?

- $\quad$ Is it necessary to improve data quality in PMS database?

\section{DATABASE EVALUATION}

Database evaluation consists of four steps: Preparation of Questionnaire and Database, Evaluation of Database, Analysis of Results, and Conclusion (Figure 1).

The construction of the questionnaire was determined by five criteria which define data quality: timeliness, integrity, validity, reliability, and precision (fletchers.atwebpages.com).

The first database evaluation was performed on 20 July 2017 by the author in the office of Jadroplov d.d., shipping company from Split, on their office PMS database. Evaluation with the use of the questionnaire was performed on four ships' databases installed on the following vessels:

- Database 1 on M/V Split,

- $\quad$ Database 2 on M/VTrogir,

- Database 3 on M/V Sveti Dujam, and M/V Peristil,

- $\quad$ Database 4 on M/V Split.

Additional evaluation was performed on office PMS database (Database 5) in the office of Brodospas d.d., another

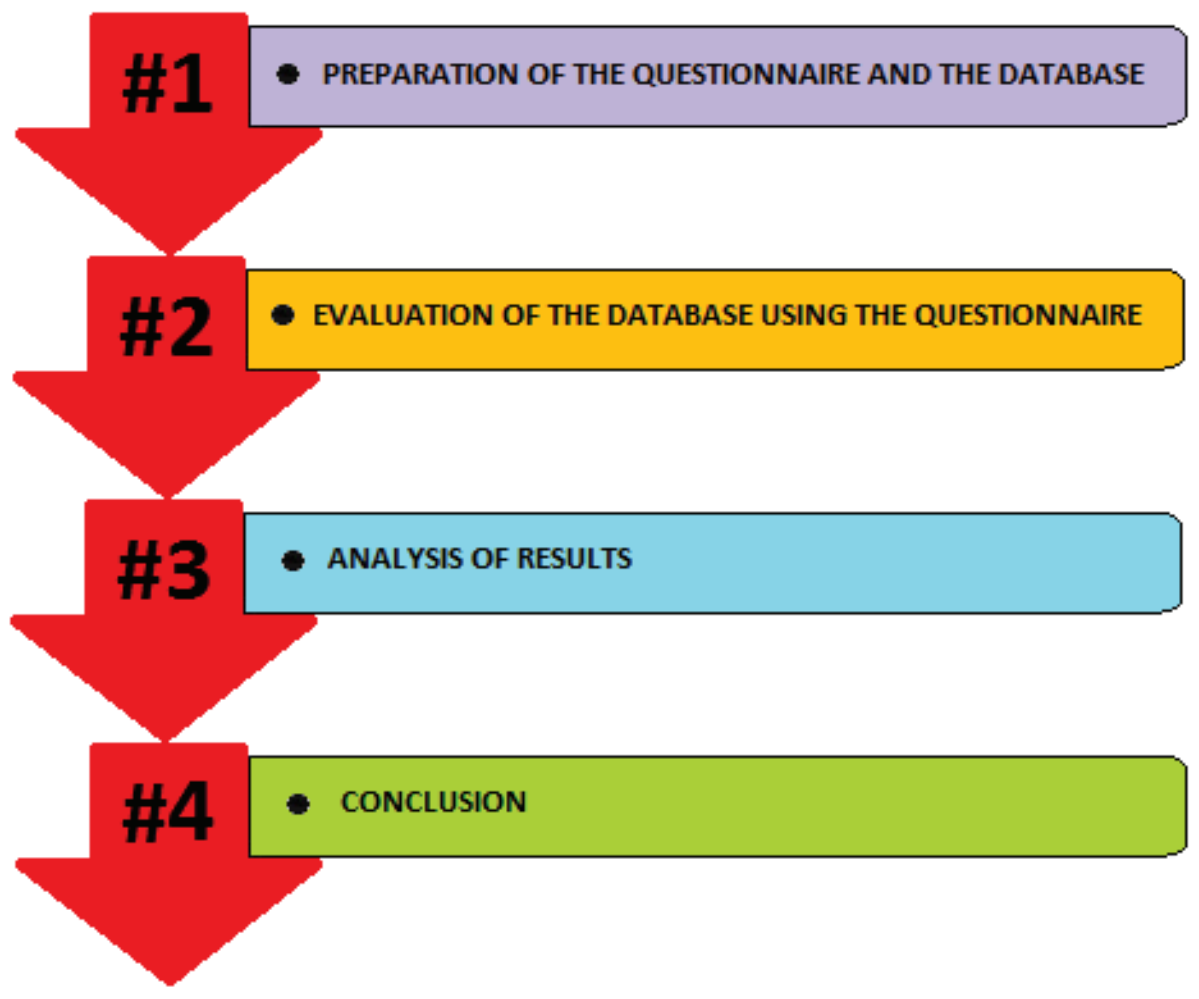

Figure 1.

PMS database evaluation process sequence diagram. 
shipping company from Split. The main purpose of the evaluation was testing of the questionnaire by a third person, real person in the real environment, not connected with the questionnaire author. The company has computerized PMS installed only on two sister vessels, and initially the databases were identical. PMS database evaluation was performed on M/V Brodospas Alpha database. The evaluation was performed on 25 July 2017 by the technical superintendent of the company, who fulfils the condition of good knowledge of computerized PMS program and good knowledge of the ship and ship's systems.

Both companies (Jadroplov d.d. and Brodospas d.d.) use the same computerized PMS program and the same DBMS. Their PMS databases for ships were developed in the same database factory.

Note: The data about the computerized PMS program, the DBMS and the data factory are withheld, and are known to the authors of this paper.

\section{QUESTIONS AND GRADES IN THE QUESTIONNAIRE}

Evaluation questionnaire consists of thirty questions arranged in six thematic groups: Machinery and equipment, Jobs inside DB, Special jobs and rules, DB jobs general, Spare parts, and Miscellaneous (Table 1). There is a field in front of every question indicating the importance of the question for the database quality. The quality of the data in the database "can directly influence all the activities linked to ship's systems" (Jurjević and Bilić, 2009). "Traffic-light principle" is used to determine the colors used in the field and to describe the importance of the question.

The questions with the red field in front have the highest importance, and the deficiencies discovered with these questions have considerable impact on the maintenance quality. All the deficiencies discovered by these questions are serious and should be rectified to improve the database and the maintenance quality.

The questions with yellow field in front have medium importance. This group of questions has also a lower impact on the database quality; the deficiencies discovered with these questions mostly influence the user's workload (unnecessary workload due to inadequate data optimization), while the influence on the maintenance quality and reliability is negligible. The deficiencies discovered with these questions should be rectified because they create unwanted consequences, i.e. unnecessary work often causes "various stresses and strains on the staff, particularly in situation where the usefulness of these reports is questionable or the staff perceives that these reports are just filed in back room drawer" (Tipgos and Trebby, 1987), and sometimes causing the complete abandonment of the computerized PMS.

The questions with the green field in front have the lowest importance, and the deficiencies discovered with these questions do not have an impact on the maintenance quality. Their impact is restricted to the overall DB appearance, and the evaluation grades to these questions are just an indicator of the attention DB construction team was paying to smaller issues. Therefore, the deficiencies discovered with these questions do not need to be rectified.

The evaluation of the data in the database is performed by a series of questions; each should be answered with a grade from 1 to 5 .

The grades should have the following meanings:

Grade 1 - Fully negative evaluation result, very few positive findings

Grade 2 - Mostly negative evaluation with a minor number of positive findings

Grade 3 - Mostly positive evaluation with a significant number of irregularities

Grade 4 - Mostly positive evaluation with a minor number of irregularities

Grade 5 - Fully positive evaluation with a negligible number of irregularities

The questions evaluated with the grade 5 are considered satisfactory and do not require any modifications to be performed in the database. The questions evaluated with the grade 4 are also considered satisfactory, and although the area for an improvement exists, DB changes are not recommended (there will be no significant quality improvement). The questions with the grades 3, 2, or 1 are considered unsatisfactory and an improvement of the data should be performed there. The schedule of the data changes in the database should be performed according to the priority of the question, red first, yellow second.

The deficiencies discovered with the green colored questions do not require rectifying. However, discovery of a significant number of deficiencies using these questions is an indication of the general negligence of DB construction team and can be an indication of a serious deficiency. In this case, a complete DB inspection is recommended.

\section{DATABASE EVALUATION}

Several factors influence computerized PMS DB evaluation listed according to their importance:

- DB purchaser,

- DB development team,

- $\quad$ DB evaluator.

As DB purchaser and DB development team create DB specification prior to its development, they determine DB content and, therefore, directly influence DB quality and the evaluation results. The DB evaluator will always be subjective, and the grades given will vary from a person to a person. Variation of the evaluating grades will be reduced with clear and concise questions, and with precise defining of the evaluation grades. 
Table 1.

Computerized PMS database evaluation questionnaire.

Area

Machinery and equipment

Jobs inside DB

DB jobs general

Spare parts

Miscellaneous

Question

Grade

\begin{tabular}{l|l|l|l|l|}
1 & 2 & 3 & 4 & 5
\end{tabular}

01. Is all machinery and equipment included in the database?

02. Is all included equipment marked properly and uniquely, according to its shipboard location and markings?

03. Is all necessary machinery divided into subcomponents (into smaller subsystems) in logical manner?

04. Does machinery or equipment have larger number of subcomponents than necessary?

05. Is there equipment or machinery listed in the database more than once, or do they have same markings or names?

06. Is data about manufacturer, type and serial number entered into all relevant items?

07. Do all equipment and machinery entries have same style, abbreviations, and markings?

08. Do all devices in DB have linked maintenance plan according to manufacturer's recommendation?

09. Are manufacturer's recommendations grouped according to devices, periods and company maintenance rules?

10. Are all jobs required by company policy included in DB? (e.g. SSM - Safety Management System)?

11. Are all jobs based on manufacturer's recommendation changed due to company policy (if exists)?

12. Are all jobs required by flag state rules and regulations included in DB?

13. Are all jobs required by class society included in DB?

14. Is there a number of minor jobs which can be grouped together?

15. Is fire detection sensor list inserted into DB together with testing plan?

16. Is alarm system and its testing program entered in DB?

17. Is PMS self-improvement program inserted into $D B$, and is there control mechanism for PMS DB self-improvement program?

18. Is critical equipment marked according to company SMS?

19. Are job descriptions written clearly?

20. Are jobs created and grouped according to multiplier principle?

21. Are all same type jobs coming from different sources synchronized?

22. Are all same jobs resulting from different requirements (sources) merged?

23. Are all required spare parts included in DB?

24. Are spare parts distributed to proper equipment and machinery?

25. Are all spare parts properly marked, do they have sufficient data for ordering?

26. Is company critical spare parts list inserted in DB?

27. Do all spare parts have same style, abbreviations, markings...?

28. Are there spare parts entered several times?

29. Are all users inserted in DB, all access rights defined in order?

30. Is there any other deficiency noted in computerized PMS database? 
As all the three factors are the same for the first four evaluated databases, it is expected that the quality of the databases should be similar as well as the evaluation grades. The expected similarity of the Database 5 compared to others should be a little lower, considering that the two influence factors are different, DB purchaser and evaluator. If questions' and grades' descriptions are created properly, the evaluation grades of Database 5 should not differ significantly.

Database evaluation grades are shown in Table 2.

\section{Table 2}

Evaluation results of computerized PMS databasest.

\begin{tabular}{|c|c|c|c|c|c|c|c|c|c|c|c|c|c|c|c|c|c|c|c|c|c|c|c|c|c|}
\hline \multirow[t]{2}{*}{ Question } & \multicolumn{5}{|c|}{ Database 1} & \multicolumn{5}{|c|}{ Database 2} & \multicolumn{5}{|c|}{ Database 3} & \multicolumn{5}{|c|}{ Database 4} & \multicolumn{5}{|c|}{ Database 5} \\
\hline & 1 & 2 & 3 & 4 & 5 & 1 & 2 & 3 & 4 & 5 & 1 & 2 & 3 & 4 & 5 & 1 & 2 & 3 & 4 & 5 & 1 & 2 & 3 & 4 & 5 \\
\hline 01. & & & & & $\mathrm{x}$ & & & & $x$ & & & & & & $x$ & & & & & $\mathrm{x}$ & & & & $\mathrm{x}$ & \\
\hline 02. & & & & $x$ & & & & & $x$ & & & & & $\mathrm{x}$ & & & & & $x$ & & & & & $x$ & \\
\hline 03. & & & & & $x$ & & & & & $x$ & & & & & $x$ & & & & & $x$ & & & & & $x$ \\
\hline 04. & & & & & $x$ & & & & & $\mathrm{x}$ & & & & & $x$ & & & & & $\mathrm{x}$ & & & & & $x$ \\
\hline 05. & & & & & $x$ & & & & & $x$ & & & & & $x$ & & & & & $x$ & & & & & $x$ \\
\hline 06. & & & & $x$ & & & & & $\mathrm{x}$ & & & & $x$ & & & & & & $x$ & & & & & $x$ & \\
\hline 07. & & & & $\mathrm{x}$ & & & & & $x$ & & & & & $\mathrm{x}$ & & & & & $\mathrm{x}$ & & & & & $x$ & \\
\hline 08. & & & & & $x$ & & & & & $x$ & & & & & $x$ & & & & & $x$ & & & & & $x$ \\
\hline 09. & & & & & $x$ & & & & & $x$ & & & & & $x$ & & & & & $x$ & & & & & $x$ \\
\hline 10. & $x$ & & & & & $x$ & & & & & $x$ & & & & & $x$ & & & & & & $x$ & & & \\
\hline 11. & $x$ & & & & & $x$ & & & & & $x$ & & & & & $x$ & & & & & & $x$ & & & \\
\hline 12. & & & $x$ & & & & & $\mathrm{x}$ & & & & & $x$ & & & & & $x$ & & & $x$ & & & & \\
\hline 13. & & & & & $x$ & & & & & $x$ & & & & & $x$ & & & & & $x$ & & & & & $x$ \\
\hline 14. & & & & $x$ & & & & & $x$ & & & & & $x$ & & & & & $x$ & & & & $x$ & & \\
\hline 15. & & & & & $x$ & & & & & $x$ & & $x$ & & & & & $x$ & & & & & & & & $x$ \\
\hline 16. & & & & & $x$ & & & & & $x$ & & & & & $x$ & & & & & $x$ & & & & $x$ & \\
\hline 17. & & & & $x$ & & & & & $x$ & & & & & $x$ & & & & & $x$ & & & & & $x$ & \\
\hline 18. & & & & & $x$ & & & & & $x$ & & & & & $x$ & & & & & $x$ & & & & $x$ & \\
\hline 19. & & & & $x$ & & & & & $x$ & & & & & $x$ & & & & & $x$ & & & & & $x$ & \\
\hline 20. & & & & $x$ & & & & & $x$ & & & & & $x$ & & & & & $x$ & & & & & & $x$ \\
\hline 21. & $x$ & & & & & $x$ & & & & & $x$ & & & & & $x$ & & & & & & $x$ & & & \\
\hline 22. & & & & & $x$ & & & & & $x$ & & & & & $x$ & & & & & $x$ & & & & & $x$ \\
\hline 23. & & & & $x$ & & & & & $x$ & & & & & $x$ & & & & & $x$ & & & & $x$ & & \\
\hline 24. & & & & $x$ & & & & & $x$ & & & & & $x$ & & & & & $x$ & & & & & $x$ & \\
\hline 25. & & & & $x$ & & & & & $x$ & & & & & $x$ & & & & & $x$ & & & & & $x$ & \\
\hline 26. & $x$ & & & & & $x$ & & & & & $x$ & & & & & $x$ & & & & & $x$ & & & & \\
\hline 27. & & & & & $x$ & & & & $x$ & & & & & & $x$ & & & & & $x$ & & & & $x$ & \\
\hline 28. & & & & & $x$ & & & & & $x$ & & & & & $x$ & & & & & $x$ & & & & & $x$ \\
\hline 29. & & & & & $x$ & & & & & $x$ & & & & & $x$ & & & & & $x$ & & & & & $x$ \\
\hline 30. & & & & & $x$ & & & & & $x$ & & & & & $x$ & & & & & $x$ & & & & & $x$ \\
\hline
\end{tabular}




\section{EVALUATION RESULTS}

The summation of grades given to each database, and the average grade value of each database are values which should be considered with reservations; the importance of the questions in DB is not the same. Therefore, the values calculated for these purposes are just an indication of the general condition of the data in DB. The summation of grades and the average grade values are shown in Table 3.

The assessment of major deficiencies serves to separate the questions where data in the DB was not in order. Questions which received lower evaluation grades (excerpt from Table 2) are in Table 4.

Table 3.

Summation of grades and average grade value.

Average grade value: summation of grades divided by the number of questions.

\begin{tabular}{llllll} 
& Database 1 & Database 2 & Database 3 & Database 4 & Database 5 \\
\hline $\begin{array}{l}\text { Summation of all } \\
\text { grades }\end{array}$ & 122 & 120 & 118 & 119 & 122 \\
\hline Average grade value & 4.067 & 4.000 & 3.933 & 3.967 & 4.067 \\
\hline
\end{tabular}

\section{Table 4.}

Questions with lower evaluation grades.

\begin{tabular}{|c|c|c|c|c|c|c|c|c|c|c|c|c|c|c|c|c|c|c|c|c|c|c|c|c|c|}
\hline \multirow[t]{2}{*}{ Question } & \multicolumn{5}{|c|}{ Database 1} & \multicolumn{5}{|c|}{ Database 2} & \multicolumn{5}{|c|}{ Database 3} & \multicolumn{5}{|c|}{ Database 4} & \multicolumn{5}{|c|}{ Database 5} \\
\hline & 1 & 2 & 3 & 4 & 5 & 1 & 2 & 3 & 4 & 5 & 1 & 2 & 3 & 4 & 5 & 1 & 2 & 3 & 4 & 5 & 1 & 2 & 3 & 4 & 5 \\
\hline 10. & $x$ & & & & & $x$ & & & & & $x$ & & & & & $x$ & & & & & & $x$ & & & \\
\hline 11. & $x$ & & & & & $x$ & & & & & $x$ & & & & & $x$ & & & & & & $\mathrm{x}$ & & & \\
\hline 12. & & & $x$ & & & & & $x$ & & & & & $x$ & & & & & $x$ & & & $x$ & & & & \\
\hline 14. & & & & $x$ & & & & & $x$ & & & & & $x$ & & & & & $x$ & & & & $x$ & & \\
\hline 15. & & & & & $x$ & & & & & $\mathrm{x}$ & & $x$ & & & & & $x$ & & & & & & & & $\mathrm{x}$ \\
\hline 21. & $x$ & & & & & $x$ & & & & & $x$ & & & & & $x$ & & & & & & $x$ & & & \\
\hline 26. & $x$ & & & & & $x$ & & & & & $x$ & & & & & $x$ & & & & & $x$ & & & & \\
\hline
\end{tabular}

The majority of the deficiencies in Table 4 are evaluated with Grade 1, indicating that the answer to the question was fully negative. The deficiencies discovered with the questions $10,11,12,21,26$ appear with all evaluated databases, and their evaluating grades are the same, or very similar. The deficiency discovered with the question 14 appears with only one database (Brodospas d.d. database), and the deficiency discovered with the question 15 with two databases. All the questions belong to the red and yellow groups of questions, while in the green group no deficiencies were found.

The deficiencies detected with the questions 11 and 21 are directly linked with the deficiencies detected with the questions 10 and 12 , i.e. resulting from them.

The resemblance analysis of the evaluation grades is made to verify the expectations that the evaluation grades will mostly look alike across all the evaluated PMS databases, with a slightly different behavior of the DB 5 . The resemblance analysis of the evaluation grades is made according to Equation 1:

$$
S=100-\frac{100}{n Q} \sum\left|R i_{b j}-R i_{b k}\right| \cdot \frac{1}{n G-1}[\%]
$$

where:

$S$ - resemblance of grades of two databases

$\mathrm{nQ}$ - total number of questions

Ri-answer to $i^{\text {th }}$ question $(i=1,2 \ldots n)$

bj $-j^{\text {th }}$ evaluated database,

bk $-k^{\text {th }}$ evaluated database; $(\mathrm{j}, \mathrm{k}=1,2 \ldots \mathrm{m}, \mathrm{j} \neq \mathrm{k})$

$\mathrm{nG}$ - total number of grades 
The resemblance analysis is shown in Table 5.

Table 5.

Comparison of resemblance of database evaluation results.

\begin{tabular}{llllll} 
& Database 1 & Database 2 & Database 3 & Database 4 & Database 5 \\
\hline Database 1 & X & $98.33 \%$ & $96.66 \%$ & $97.50 \%$ & $90.00 \%$ \\
\hline Database 2 & $98.33 \%$ & X & $95.00 \%$ & $95.83 \%$ & $90.83 \%$ \\
\hline Database 3 & $96.66 \%$ & $95.00 \%$ & X & $99.17 \%$ & $86.66 \%$ \\
\hline Database 4 & $97.50 \%$ & $95.83 \%$ & $99.17 \%$ & $X$ & $87.50 \%$ \\
\hline Database 5 & $90.00 \%$ & $90.83 \%$ & $86.66 \%$ & $87.50 \%$ & $X$ \\
\hline
\end{tabular}

The resemblance analysis of database evaluation results showed great resemblance of all Jadroplov d.d. databases, while the results of Brodospas d.d. database resemblance analysis are slightly lower. The comparison of resemblance confirmed the expected evaluation results, as it is written in the heading "Database evaluation".

\section{DISCUSSION}

The evaluation results analysis showed several results: A - The summation of all the grades, as the first criterion, gave quite an equalized result; variations among the databases are very small.

B - The average grade value of every single tested database is satisfactory. If we compare the average grade value with the system of grades given above, every single database was awarded with "Mostly positive evaluation with smaller amount of irregularities" (Grade 4).

C - The resemblance of the evaluated databases is very high.

The analysis of the deficiencies showed that most of them are the same on all the databases, and are connected with the jobs related to the company experience, ISM or SMS Code, and flag state rules and regulations. This fact indicates a potential shortcoming during the process of creating the description of the DB (the list is created for DB specification and agreed by the purchaser and the development team) and to an insufficient control of the inserted data and an insufficient evaluation of the data after the DB was developed. The repetition of the same deficiencies across all the evaluated databases indicates the possibility of DB development team as the key factor which caused the repetition of the deficiencies. This claim is dubious because the evaluated sample is too small.

The deficiencies discovered with the questions 14 and 15 appear with only two evaluated databases. The reason for them seems to be the absence of instruction books (information) during DB construction.
The third database evaluation stage, analysis of the evaluation (Pipino et al., 2002), presented the following results:

An improvement of the evaluated databases should be performed to rectify the discovered deficiencies (see Table 4). After finishing with the improvement of the data, a new evaluation should be performed with the use of the questionnaire.

- Database specification and contraction process between the purchaser and the construction team should be improved for better data quality in DB.

- Data checking during the construction and DB evaluation process before DB delivery should be improved to prevent the use of databases with deficiencies.

\section{CONCLUSION}

Good data quality in PMS DB is the basic condition for a normal operation of the Planned Maintenance System and, consequently, for the quality of maintenance. The evaluation of the data quality is a process which requires knowledge and competence from the DB evaluator and a well-defined evaluation system to achieve a relevant and reliable evaluation result. The absence of a unique and well-defined process of DB contracting, supervision, and evaluation leads to a major problem described in this paper, which is the repetition of the same mistake from DB to DB.

The data quality checking system described in the paper is based on the evaluation of database using a specifically designed questionnaire. The questionnaire fulfilled its purpose, first during the test period, and later in use by the end user. The evaluation grades of all the databases showed high resemblance, and that fact shows that the questions in the questionnaire and the description of grades are formulated well, with clarity and precision. This caused a decrease in variation of the grades and DB evaluator's potential subjectivity.

The evaluation of the database with the use of the questionnaire determined the areas where the data in DB can 
be improved and pinpointed some potentially weak spots in DB development process. The average grade value and the noted deficiencies during the data evaluation are a good indicator of the complete database condition.

It has been proved that the questionnaire is a useful tool for the evaluation of the data in PMS DB and as help for all the persons involved in DB contraction and construction process. The use of the questionnaire has proven to be simple and the results obtained are reliable.

During the evaluation and the analysis of the results a possible new claim appeared. It appears that DB development team is the key factor for the repetition of the deficiencies; therefore, the key factor in the whole process of database construction. This claim can redefine the order of importance factors that influence computerized PMS DB quality. This claim is still not confirmed and requires a completely new research.

\section{ACKNOWLEDGEMENTS}

We would like to express our gratitude to the Technical Departments and the Technical Managers of the companies Jadroplov d.d. and Brodospas d.d. for their help and assistance during the process of the evaluation of their computerized PMS databases, and for the permission to publish the results obtained.

\section{REFERENCES}

Batini, C., Cappiello, C., Francalanci, C. and Maurino A., (2009), Methodologies for Data Quality Assessment and Improvement, ACM Computing Surveys, 41(3), 6. https://doi.org/10.1145/1541880.1541883

Jurjević, M. and Bilić, B., (2009), Reliability Calculation of Marine Propulsion System Applying the Data from the Software Package Amos, Naše more 56(3-4), pp. 108117.

Machinery Survey Arrangements, (2003), in: DNV Rules for Classification of Ships, Høvik, Norway: Det Norske Veritas, available at: https://rules.dnvgl.com/docs/pdf/ DNV/rulesship/2004-01/ts708.pdf, [accessed 27 July 2017.].

Pipino, L. L., Lee, Y. W. and Wang, R. Y., (2002), Data Quality Assessment, Communications of the ACM, 45(4), pp. 211- 218.,

https://doi.org/10.1145/505248.506010

Revised ISM Code, (2015), available at: https://www.classnk.or.jp/hp/pdf/activities/ statutory/ism/ISM_Cd/ISM-Code-e.pdf, [accessed 27 July 2017.].

Tayi, G. K. and Ballou, D. P., (1998), Examining Data Quality, Communications of the ACM, 41(2), pp. $54-57$

https://doi.org/10.1145/269012.269021

Tipgos, M. A. and Trebby, J. P., (1987), Job-Related Stresses and Strains in Management Accounting, The Journal of Applied Business Research, 3(3), pp. 8 - 14. https://doi.org/10.19030/jabr.v3i3.6510

Unknown, Fletcher Business Solutions, available at: http://fletchers.atwebpages. com/BusinessManagement/Monitoring,\%20Evaluation\%20\&\%20Reporting/ FKCFADQ.htm, [accessed 27 July 2017.]. 